\title{
Bolivia 2013: Al CALOR PREELECTORAL
}

\author{
Bolivia 2013: Feeling the Pre-electoral Heat
}

\section{MARTÍN MENDOZA-BOTELHO}

Eastern Connecticut State University, Estados Unidos

\begin{abstract}
RESUMEN
El 2013 en Bolivia se caracterizó por una agenda política en rumbo a las elecciones del próximo año. Los principales logros estuvieron relacionados a una bonanza económica que continúa, y que en gran parte se debe a un manejo responsable de la economía y a un contexto internacional favorable para sus principales bienes de exportación, como lo son el gas y la agroindustria. Sin embargo, la sombra de la corrupción continúa ante un ineficiente sistema de justicia, lo que es preocupante en un Estado que sigue en expansión. La agenda internacional también fue bastante activa, y se destacaron las muestras de solidaridad de países de la región ante el inusual evento relacionado al avión presidencial que fue forzado a aterrizar en Viena en violación a normas internacionales. Pero al mismo tiempo, Bolivia demostró una vocación de liderazgo internacional al convertirse en la futura sede del cincuenta aniversario de los países en desarrollo del G77 + China en la ONU y uno de los pocos países de la región en poner un satélite en órbita. Este año también mostró a un sólido y popular presidente Morales favorito para las próximas elecciones, contra una oposición que permanece dividida.
\end{abstract}

Palabras clave: Bolivia, Evo Morales, elecciones presidenciales, TIPNIS, gobernabilidad en Latinoamérica.

\begin{abstract}
Bolivia's political agenda in 2013 was characterized by a pre-electoral political agenda. Some of the important accomplishments of this country were related to an economic bonanza that continues, which in part is the result of sound macroeconomic management and a favorable international context for some of its main commodities, such as gas and agroindustry. However, the shadow of corruption continues in a country with an inefficient justice system and an expanding state. The international agenda was also very active. One of the highlights was the forced landing of the presidential plane in Vienna in violation of international norms, which triggered the strong solidarity of countries in the region. But Bolivia also demonstrated international leadership by assuming the challenge of organizing the $50^{\text {th }}$ anniversary of the G77 + China group at the United Nations, and for being one of the few countries in this region to put a satellite in orbit. This year also showed President Morales as the favorite candidate for the upcoming elections, against an opposition that remains divided.
\end{abstract}

Key words: Bolivia, Evo Morales, presidential elections, TIPNIS, governance in Latin America. 


\section{TEMAS SALIENTES EN LA REALIDAD NACIONAL Y SU IMPACTO POLÍTICO}

\section{Coyuntura económica}

\section{Continúa el sólido crecimiento económico}

Sin lugar a dudas, uno de los aspectos favorables de los últimos tiempos en Bolivia ha sido el elevado crecimiento económico, estimado por la Comisión Económica para América Latina y el Caribe de las Naciones Unidas (CEPAL-UN) en 6,4\% para el 2013. Este crecimiento es uno de los más altos de la región, estimado por el Fondo Monetario Internacional (FMI) en 2,75\%, y comparado con el estimado global del 3\%. Esta cifra pone a la economía boliviana como una de las de mejor desempeño en Latinoamérica, detrás de Paraguay, que tuvo una notoria recuperación con un crecimiento estimado del $13,0 \%$. De acuerdo con el presidente Morales, parte del éxito económico se encuentra en la creciente participación del Estado en las actividades económicas, que se estima en algo más de un tercio (35\%). Este nuevo enfoque económico se encuentra respaldado por cambios legislativos como la nueva Ley de la Empresa Pública (Ley No 4662013), que hace explícita la participación del Estado en la economía. Sin embargo, a pesar de las varias nacionalizaciones (y los argumentos de la oposición en cuanto a las intenciones del gobierno a largo plazo), el sistema económico boliviano sigue siendo híbrido. En palabras del propio presidente Morales: "El sector privado no puede ponerse celoso, más bien deberían complementarse empresas del Estado con las privadas, eso es parte de la economía plural" (La Razón, 2013 g). El panorama económico es alentador también a futuro, ya que se proyecta que Bolivia tendrá otro elevado nivel de crecimiento en el 2014, estimado por la CEPAL en 5,5\%, lo que pone a Bolivia a la par del Perú, país que también es visto como de alto desempeño. Si bien estas noticias son alentadoras, los detalles vuelven a mostrar una alta dependencia de ciertos sectores, como los hidrocarburos, que debido a las inversiones estratégicas en el 2013 logró un crecimiento del 18,3\%, seguido de mejoras en los sectores de construcción $(8,6 \%)$, transporte $(8,1 \%)$ y manufacturas $(6,7 \%)$. Una de las sorpresas fue el bajo crecimiento del sector minero de solo $1,3 \%$, lo que en parte refleja condiciones cambiantes en los mercados internacionales con la caída de precios para algunos de los minerales que el país exporta.

Una buena parte del éxito económico, por lo tanto, se explica por la relativa eficiencia del sector de hidrocarburos, específicamente las labores de Yacimientos Petrolíferos Fiscales de Bolivia (YPFB), favorecida por un contexto internacional favorable. Pero la estrategia general en el sector de hidrocarburos contempló inversiones no solo para expandir la capacidad productiva (exploración y explotación), sino también con miras a una mayor industrialización (mejoras a la red de distribución) y consumo interno (conexiones domiciliarias). En el 2013 la inversión en el sector petrolero alcanzó US\$1.835 millones (ver Figura 1), un récord en la inversión pública no visto desde la bonanza petrolera de principios de los setenta. Es más, el gobierno estima que la inversión en el 2014 crecerá en 65\% (estimada en US\$ 3.029 millones, La Razón, 2013d). Estos datos muestran la importante apuesta del gobierno a los futuros réditos en este sector. Para el tamaño de la economía boliviana, los niveles de producción del 2013 tanto de gas natural (58 millones 
Figura 1. Reservas internacionales netas (RIN) e inversión en hidrocarburos de YPFB (Bolivia 2001-2014)

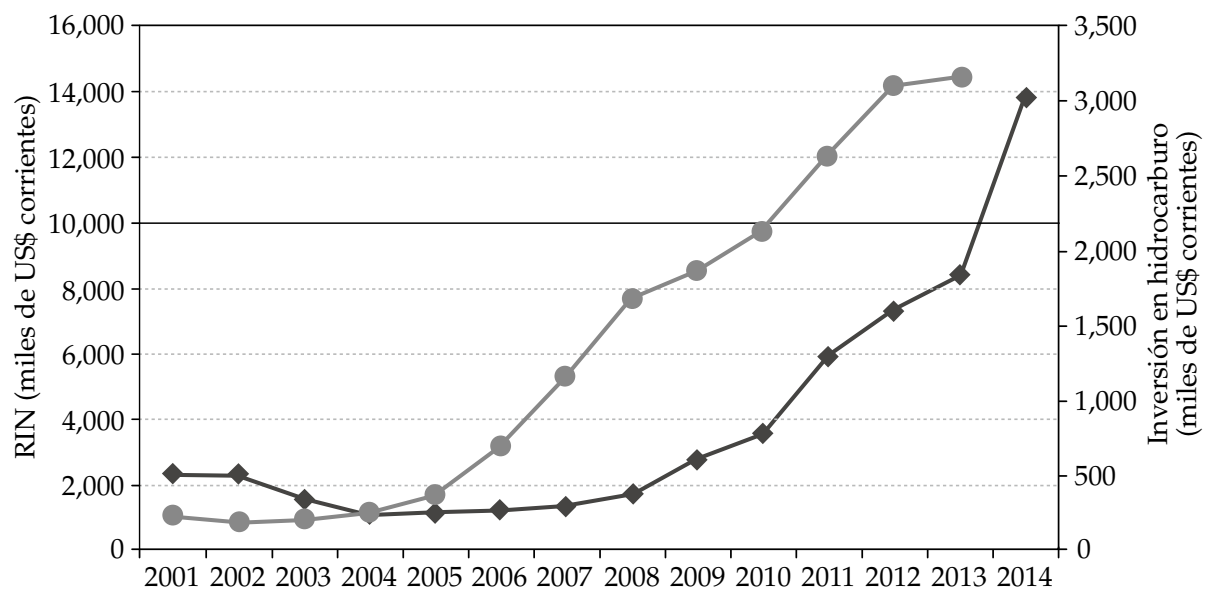

—- Reservas internacionales netas (RIN) ——Inversiones en hidrocarburo

de metros cúbicos) y petróleo (59.000 barriles por día) son sumamente significativos y constituyen el pilar de los ingresos públicos. Se estima que las recaudaciones logradas tanto por regalías, el impuesto directo a los hidrocarburos (IDH), participaciones y patentes alcanzó US\$ 5.585 millones, un incremento del 30\% respecto de 2012.

En el 2013 también continuó la estrategia de estatización con la nacionalización del paquete accionario de la firma Servicios de Aeropuertos Bolivianos S.A. (SABSA) en febrero vía decreto, que hasta entonces pertenecía al consorcio español Abertis y Aena. El argumento detrás de esta nacionalización estuvo ligado a la baja inversión de SABSA en el mejoramiento de la estructura aeroportuaria. De acuerdo con el Ministerio de Obras Públicas, en el 2005 SABSA se comprometió a invertir US\$ 53,4 millones hasta el 2022, y al menos US $\$ 26$ millones hasta el 2011, pero solo habían invertido US $\$ 5$ millones, a pesar de sus elevados niveles de utilidad estimados. Esta nacionalización nuevamente se dio a pesar de los esfuerzos diplomáticos de España, cuyas empresas fueron afectadas en más de una vez como fue el caso de la petrolera REPSOL. Por su parte, Abertis y Aena esperan lograr una indemnización del Estado boliviano por al menos US\$ 90 millones vía arbitraje internacional.

El efecto político de estas cifras económicas fue muy claro, ya que validan el éxito relativo del modelo económico, que pone énfasis en la participación económica del Estado promulgado por la administración del MAS-IPSP (Movimiento al SocialismoInstrumento Político para la Soberanía de los Pueblos, abreviado, luego simplemente como MAS). Sin embargo, estas cifras también muestran la vulnerabilidad de la economía debido a su dependencia en un par de sectores, lo que eventualmente puede traducirse en un conflicto político. Este es el caso del sector minería (que se discute luego), con un creciente número de mineros asalariados dependientes del Estado, lo que revive la 
tradición gremial que caracterizó a Bolivia en la segunda mitad del siglo XX. Pero es importante resaltar que esta relativa bonanza económica viene acompañada de un buen manejo macroeconómico, tal como lo revelan otras cifras significativas. Por ejemplo, el nivel de inflación estimado para el 2013 fue de $6,5 \%,{ }_{1}^{1}$ ligeramente superior a la cifra del 2012 de 4,5\%, pero comparativamente uno de los más bajos de la región contrastando la tendencia inflacionaria en varios países de Latinoamérica como es el caso de Argentina con una inflación estimada por analistas extranjeros del 28\% (que contrasta las cifras oficiales de su gobierno del 11\%). El desempleo estimado para el 2013 fue de 7,4\%, cifra similar a la de años anteriores. ${ }^{2} \mathrm{Si}$ bien esta cifra muestra que existe una cierta estabilidad en el mercado laboral, no refleja en su totalidad uno de los principales desafíos de la economía boliviana que es la informalidad y la precariedad del empleo. Otro indicador altamente significativo del 2013 fueron las nuevas cifras de superávit fiscal estimadas por el Banco Mundial en 2,0\%. Independiente del monto específico, este indicador muestra una cierta robustez en las cuentas públicas, lo que ha permitido a la administración de Morales un buen control sobre la economía reduciendo la dependencia en organismos financieros internacionales. Estos abultados ingresos fiscales también han permitido incrementar el nivel de Reservas Internacionales Netas (RIN), que alcanzaron 14.430 millones de dólares (en moneda extranjera y reservas de oro) en el 2013, otro récord histórico (ver Figura 1). Esto significa un crecimiento del 12,2\% respecto del balance del 2013, y con proyecciones del Banco Central de Bolivia de continuar acumulando reservas durante el 2014 (estimación inicial de un incremento del 3,9\%). Sin embargo, el gobierno ya ha puesto en marcha el Fondo para la Revolución Industrial Productiva (Finpro), cuyo principal objetivo es el de financiar proyectos productivos de gran envergadura. En el 2013 el Finpro recibió recursos por US\$ 1.200 millones, mismos que tienen como primeros programas el anhelado proyecto de teleférico en la ciudad de La Paz y el tren de Bulo Bulo en Santa Cruz.

Uno de los grandes desafíos económicos, por lo tanto, es la redistribución de estos recursos. Esta discusión generó bastante polémica en el 2013, y curiosamente se centró en los resultados oficiales del Censo de Población y Vivienda del 2012 elaborado por el Instituto Nacional de Estadística (INE). Una buena parte de los recursos fiscales en Bolivia se distribuyen a base de criterios poblacionales utilizando datos censales. Por lo tanto los esperados resultados oficiales del Censo 2012, previstos para principios del 2013, generaron una gran expectativa, sobre todo en los departamentos con mayor crecimiento demográfico como Santa Cruz. Asimismo, estos datos censales también debían ser utilizados para recalcular distritos electorales para futuras elecciones, incluyendo la elección presidencial del 2014. El conflicto en este tema surgió por la negativa del gobierno en publicar los resultados oficiales del censo, lo que causó malestar en la oposición y en varios de los gobiernos regionales. La principal crítica estuvo relacionada a una posible

Datos del Instituto Nacional de Estadística (INE) de Bolivia.

Los datos de desempleo y superávit fiscal provienen del World Factbook de la Agencia de Inteligencia de los Estados Unidos (CIA) con datos del Banco Mundial.

3 Esta cifra contrasta la del Ministerio de Economía de 4,5\% de superávit, y que Morales ha utilizado en varios discursos. 
manipulación de aspectos técnicos por el gobierno como son los datos censales con fines políticos. Si bien los datos censales fueron finalmente publicados a fines del 2013, este episodio demostró nuevamente una fragilidad institucional crónica.

\section{Coyuntura política}

\section{Año preelectoral y conflicto en las bases}

Sin lugar a dudas, la agenda preelectoral fue prominente en el 2013. Por el lado del oficialismo la popularidad de Morales se mantiene, a pesar del resquebrajamiento de las relaciones con algunas de sus bases sociales. Posiblemente los casos que mejor ilustran el cambiante escenario político fueron las pugnas internas en las dos organizaciones indígenas más representativas del país, el Consejo Nacional de Ayllus y Markas del Qullasuyu (Conamaq) y la Confederación de Pueblos Indígenas de Bolivia (CIDOB). Ambas organizaciones forman parte del denominado Pacto de Unidad creado en el 2004 con el propósito de promover la Asamblea Constituyente. La división interna del Conamaq, con una corriente de notable raíz indígena y crítica al MAS y con otra de tinte reformista y leal a Morales, ya se venía acrecentando en los últimos años. Las razones son diversas, pero incluyen el tema inconcluso de la carretera que atravesaría el Territorio Indígena y Parque Nacional Isiboro Sécure (TIPNIS) y las intenciones de Conamaq de mantenerse como organización independiente. Esta brecha ideológica finalmente tomó forma con los esfuerzos de ambos bandos de controlar la organización. A mediados de septiembre, el grupo afín al MAS intentó tomar por la fuerza la sede de esta organización en La Paz. Los meses siguientes fueron de negociación, pero finalmente el 10 de diciembre se desató la violencia y esta facción tomó la sede de la Conamaq y eligiendo a Hilarión Mamani como máximo dirigente (con un saldo de varios heridos). El grupo de oposición también respondió con la elección de nuevas autoridades en un Jach'a Tantachawi (en aymara, gran reunión), con Freddy Bernabé a la cabeza. El gobierno intervino para mediar en el conflicto, pero con la denuncia de Bernabé de que la policía tomó el lado de Mamani, ya que les impidió retornar a su sede. Esto condujo a una huelga de hambre de cuatro días en la puerta de la sede de la organización, en constante acoso por el grupo de Mamani. Como resultado, una de las organizaciones sociales más emblemáticas quedó dividida entre oficialistas y opositores.

De manera anecdótica, el conflicto interno de Conamaq también atrajo inusitada atención internacional ante la amenaza del exdirigente Rafael Quispe de sabotear el famoso Rally Dakar durante su paso por Bolivia. El Rally Dakar (antiguamente conocido como ParisDakar) es uno de los eventos automovilísticos más prestigiosos en el mundo y se corre en Sudamérica desde el 2009. A fines de diciembre, Rafael Quispe, en apoyo a Bernabé, amenazó con bloquear el paso del Rally Dakar como medida de presión para que la policía levante el cerco a las instalaciones. Además, exigía que los organizadores de la competencia soliciten la autorización explícita de los pobladores indígenas de Potosí por donde pasaría el Rally, aunque con mínimo apoyo de las bases. La reacción de Morales, quien desde un inicio apoyó este evento, fue inmediata y las amenazas de Quispe fueron 
respondidas con la decisión oficial de no permitir ningún tipo de protestas que afecten el desarrollo de esta competencia internacional. A pesar del revuelo mediático se espera que el Rally Dakar 2014 sea realizado en enero de ese año sin mayores complicaciones.

Paralelamente, la CIDOB tuvo los mismos problemas de legitimidad interna. Al igual que en la Conamaq, surgieron dos corrientes distintas en su interior, una afín al gobierno y otra en oposición al MAS. La crisis interna de la CIDOB (que aglutina a 34 pueblos indígenas) se acrecentó en septiembre con la elección de nuevas autoridades. Por un lado, durante la XVI Gran Asamblea Nacional de los Pueblos Indígenas (Ganpi) la dirigente indígena Melva Hurtado del pueblo Moré del Beni fue elegida junto a otros 13 representantes para liderar la organización hasta el 2017. Sin embargo, a cinco calles de distancia el dirigente Adolfo Chávez (quien fue uno de los líderes instrumentales de la IX Marcha por el TIPNIS del 2012) denunció que estos líderes estaban al servicio del gobierno y llamó a las organizaciones de la CIDOB a desconocer su mandato. Parte de su argumento se relacionaba a la baja representación de pueblos indígenas en el Ganpi, y que refleja el malestar por el todavía irresuelto tema del TIPNIS. La reacción oficial fue directa. El gobierno no solo reconoció a la nueva dirigencia, sino que también aprobó un financiamiento directo para la CIDOB de Bs. 8,3 millones, tanto para actividades como para infraestructura. El anuncio de este financiamiento lo hizo el propio presidente Morales durante una ceremonia oficial el 3 de octubre en la conmemoración de los 31 años de existencia de la CIDOB. Asimismo, los dirigentes indígenas que asistieron al evento nombraron al presidente Morales como el "Primer Cacique General, cacique de caciques" (Página Siete, 2013). Por su parte, la sección de la CIDOB presidida por Chávez celebró de manera paralela el mismo hito organizacional en la subcentral del TIPNIS.

Las divisiones internas de la CIDOB y Conamaq quedaron irresueltas el resto del 2013. Sin embargo, el 23 de diciembre el presidente Morales se reunió con los representantes afines al gobierno, a pesar de que estas dos organizaciones permanecían con dirigencias paralelas. Este esfuerzo de reintegración, que también incluyó a la Confederación Sindical Única de Trabajadores Campesinos de Bolivia (CSUTCB), la Confederación Nacional de Mujeres Campesinas Indígenas Originarias de Bolivia-Bartolina Sisa y la Confederación Sindical de Comunidades Interculturales originarios de Bolivia (CSCIB), refleja las intenciones del MAS de reconectarse con sus bases en este periodo preelectoral. Al final de la reunión todas estas organizaciones anunciaron su apoyo directo a la reelección de Morales.

\section{Día del Trabajo}

Como ya se ha hecho tradición, el presidente Morales aprovechó el Día del Trabajo (primero de mayo) para hacer anuncios de reformas significativas en su administración. Las reformas anunciadas este año tuvieron un doble objetivo, doméstico e internacional. Por un lado Morales anunció la expulsión de la Agencia de Cooperación de los Estados Unidos en Bolivia (siglas en inglés, USAID). Si bien las relaciones entre la administración de Morales y los Estados Unidos siempre fueron problemáticas, este hecho no dejó de sorprender a los analistas (Los Tiempos, 2013) Esta decisión refleja el continuo deterioro 
de las relaciones bilaterales que entre otros significó la expulsión del embajador Philip Goldberg en septiembre del 2008 (que Estados Unidos respondió con la expulsión de su homónimo Gustavo Guzmán y que significó un vacío diplomático por varios años) bajo acusaciones de injerencia política en asuntos internos. Esta acción fue seguida por la sonada expulsión del Departamento Antidrogas de los Estados Unidos (siglas en inglés, DEA) en noviembre del mismo año bajo acusaciones de espionaje y conspiración. Sin embargo, el trabajo de USAID venía siendo coordinado con el gobierno de Morales desde el 2011 bajo un acuerdo marco promovido por la administración de Barack Obama con el fin de establecer relaciones más equitativas con Latinoamérica. Parte del acuerdo significaba la inversión de alrededor de 22 millones por USAID en programas de salud. Sin embargo, el trabajo de USAID estuvo relacionado a la estrategia general de erradicación de coca, por ejemplo en la promoción de cultivos alternativos. Pero también afectaron los conflictivos comentarios del nuevo Secretario de Estado John Kerry en abril de ese año, quien declaró (sic): "El Hemisferio Occidental es nuestro patio trasero, es de vital importancia para nosotros. A menudo, muchos países en el Hemisferio Occidental sienten que los Estados Unidos no les presta suficiente atención y a veces es posible que esto sea cierto. Tenemos que estar más cercanos y planeamos hacerlo" (traducción del autor). Por lo tanto, Morales fue enfático en cuanto a relacionar la expulsión de USAID con los comentarios de Kerry, y calificó este hecho como una "protesta" a la política exterior de Estados Unidos. Si bien el efecto económico del cierre de USAID es limitado, el efecto político es de gran significación, ya que simboliza el consistente mensaje anticolonialista de la administración del MAS que califica a muchas de las acciones de política externa de los Estados Unidos como imperialistas.

Las otras medidas del primero de mayo fueron principalmente económicas y para algunos con fines electorales. La medida más discutida fue el incremento salarial de entre 7 y 13 por ciento para el sector público (estimado en alrededor del $8 \%$ de la masa salarial del país), que incluso iba de manera retroactiva desde enero del 2013. La reacción social fue inmediata, ya que si bien esta medida apuntaba a mejorar las condiciones laborales de los trabajadores del Estado, ignoraba el hecho de que la mayoría de los trabajadores se encuentran en el sector informal, acentuando la existente brecha salarial entre asalariados e informales. ${ }^{4}$ A esta medida se sumó el anuncio de incrementar la Renta Dignidad en Bs. 50 (aproximadamente US\$ 7,2), lo que beneficia a un importante porcentaje de la población. Finalmente, Morales anunció el incremento de su propio salario, lo que permitiría hacer un ajuste general a los salarios de la administración pública en general, ya que por norma ningún funcionario público puede percibir un salario más alto que el del Presidente. El incremento anunciado era un monto equivalente a 15 salarios mínimos (Bs. 18.000 o alrededor de US\$2.600 al mes), lo que demuestra nuevamente la gran brecha salarial en Bolivia y que refleja la alta inequidad existente en esta sociedad.

4 Otro evento significativo que merece ser mencionado fue la instauración del "doble aguinaldo" (Decreto Supremo 18012 del 22 de noviembre de 2013) para todos los trabajadores asalariados; lo que también causó cierto malestar tanto por las implicaciones económicas para el Estado y las empresas privadas, así como en sectores que no perciben un ingreso salarial formal. 
Este malestar se canalizó en la que posiblemente fue la mayor movilización del 2013, promovida por una reemergente Central Obrera Boliviana (COB) bajo el nuevo liderazgo de Juan Carlos Trujillo. La demanda de la COB se concentró en la solicitud de una pensión de Bs. 8.000 (aproximadamente US\$1.150) para los mineros que aportaron 35 años y de Bs. 5.000 para otros sectores. El problema de fondo, sin embargo, es el aún irresuelto tema de pensiones. Desde el 2010 el gobierno ha estado haciendo gestiones para transferir nuevamente al sector público la administración de pensiones, aunque una buena parte permanece administrada por entidades privadas vía Administradoras del Fondos de Pensiones (AFPs), creadas a fines de los años 90 durante las reformas neoliberales. El pliego de peticiones de la COB precisamente hacía explícita su intención de participar en este nuevo proceso del manejo de pensiones. Esta cruzada laboral permitió a la COB reocupar un espacio en la agenda político-sindical. Durante la huelga, la participación de los mineros de Huanuni fue fundamental, ya que dio un espacio sólido de resistencia, además de ocasionar pérdidas económicas de significación para el Estado. Pero esta movilización también atrajo a los aliados gremiales tradicionales de la $\mathrm{COB}$, como lo son los sectores de educación y salud. La reacción del gobierno fue mixta, ya que si bien la represión policial y los esfuerzos para romper los bloqueos fueron contenidos, eventualmente el gobierno declaró el paro y la huelga ilegal y amenazó con una serie de sanciones, incluyendo descuentos por días no trabajados y la posibilidad de despido.

Esta situación forzó la negociación con el gobierno a la ofensiva, pero con una COB que demostró que todavía tiene la capacidad de movilizar diversos sectores sociales a nivel nacional. Finalmente, el 21 de mayo, luego de 15 días de huelga de hambre, la COB aceptó la propuesta del ejecutivo que establece una jubilación de Bs. 4.000 para mineros y Bs. 3.200 para otros sectores. En el caso de educación, el ministro de ese rubro anunció que la multa a los maestros por días inactivos, en 7.498 unidades educativas, ascendía a Bs. 15 millones, una cifra récord en cuanto a sanciones públicas (La Razón, 2013a). El Magisterio respondió con otra ronda de movilizaciones y protestas, las que fueron apoyadas por la COB.

\section{Oposición dispersa}

La cercanía de las elecciones presidenciales previstas para diciembre del 2014 obligaron a una dispersa e ideológicamente débil oposición a movilizarse. En el 2013 la mayor fuerza de oposición se concentró en el denominado "Frente Amplio", que aglutina a varios sectores mayoritariamente de izquierda, y que posiblemente sea el principal rival del MAS. Sin embargo, los sondeos de intención de voto del 2013 muestran que todavía existe una brecha amplia entre el MAS y sus rivales (ver Figura 2). El liderazgo del Frente recayó en Samuel Doria Medina, líder del partido Unidad Nacional, dueño de varias empresas y político de larga trayectoria. Otras figuras que destacan incluyen a Loyola Guzmán, exasambleísta constituyente por el MAS y exguerrillera del Ejército de Liberación Nacional (ELN) fundado por Ernesto "Che" Guevara en 1967; José Antonio Quiroga, hijo del conocido dirigente izquierdista Marcelo Quiroga Santa Cruz asesinado durante la represión de los años ochenta; y Rafael Quispe, exdirigente de la Conamaq. A diferencia del MAS, con la nominación indisputable del binomio Morales-García 
Figura 2. Intención de voto elecciones presidenciales 2014 (junio-julio 2013)

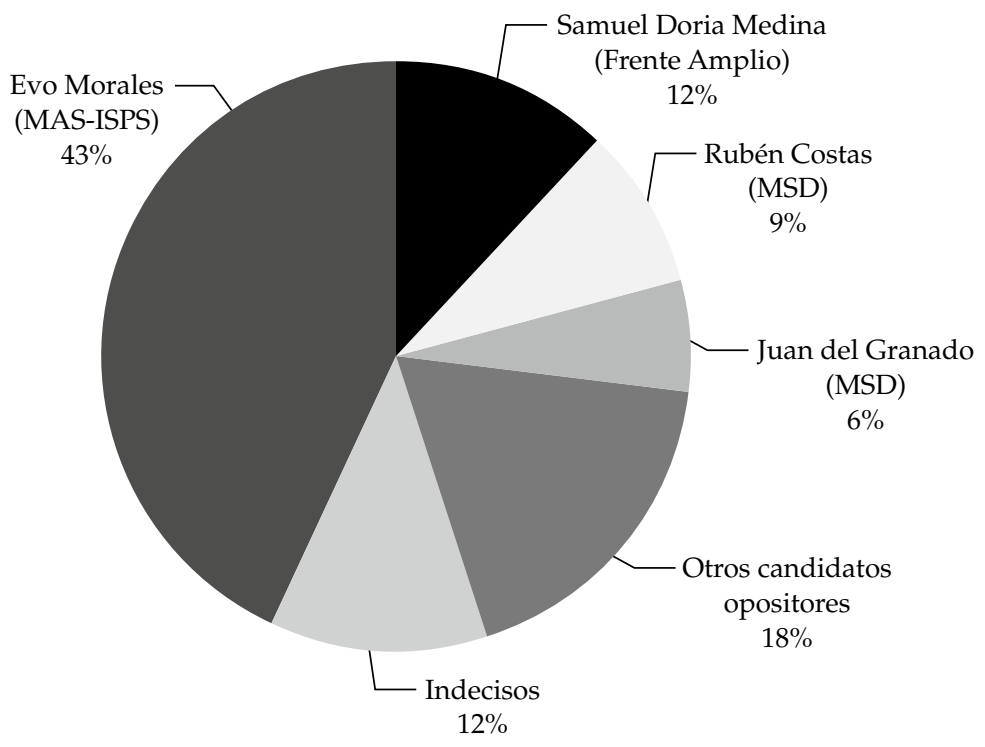

Linera, el Frente aseguró que en el 2014 recurrirá a un sistema democrático interno para la selección de todos los candidatos, incluso el de Presidente.

Otra fuerza opositora activa en el 2013 y con claros objetivos electorales la constituyó el Movimiento Sin Miedo (MSM), con el exalcalde de La Paz Juan del Granado a la cabeza. Desde su distanciamiento del MAS en el 2009, el MSM ha servido como un partido de tinte intelectual de izquierda y todavía con notable influencia en ciudad de La Paz, con el control de la alcaldía más grande del país. Sin embargo, la proyección nacional del MSM es limitada y las encuestas iniciales de intención de voto le dan una baja popularidad. En esta corriente opositora también se encuentra la denominada Convergencia Nacional $(\mathrm{CN})$, que constituye el remanente de la agrupación Poder Democrático y Social (Podemos) del expresidente Jorge "Tuto" Quiroga y varios grupos simpatizantes de la agenda autonómica del Oriente. Si bien CN todavía mantiene varios diputados en el Asamblea Plurinacional, no existe una noción de liderazgo clara ante la ambigua y reticente posición que adoptó Jorge Quiroga en este período preelectoral. Cercana a esta fuerza también se encuentra el gobernador de Santa Cruz Rubén Costas, con el denominado Movimiento Social Demócrata (MSD) que además de sus seguidores en ese departamento, los Verdes, incluye a los exprefectos opositores de Chuquisaca, la carismática Savina Cuéllar y del Beni, Ernesto Suárez, además del sector de CN ligado al excandidato presidencial Manfred Reyes Villa, quien permanece en los Estados Unidos con pocas posibilidades de retornar, ya que tiene una docena de procesos en su contra por actos de corrupción (dos de ellos con sentencia).

En el 2013, como se muestra en la Figura 2, el presidente Morales lideró las encuestas de intención de voto, pese a la fragmentación de algunas de sus bases sociales como los casos mencionados de CONAMAQ y CIDOB. Su popularidad subió incluso en Santa 
Cruz, sede del movimiento autonómico y de la oposición más sólida durante todo su mandato. Parte de estos resultados, como ya se discutió, responden a una oposición dispersa con dificultades de proponer un modelo político distinto, a una economía robusta y a un par de eventos internacionales que generaron simpatía hacia Morales, como el caso del avión presidencial que se discute luego.

De acuerdo con el sondeo de intención de voto del periódico Página Siete, ${ }^{5}$ a mediados del 2013 la intención de voto favorecía a Morales con el 45\%, seguido de lejos por Samuel Doria Medina (12\%), Rubén Costas (9\%) y Juan del Granado (6\%). La intención de voto para el resto de posibles candidatos de oposición fue del 18,5\%. De mantenerse estos resultados, Morales sería elegido automáticamente, ya que de acuerdo con la Constitución los candidatos necesitan 50\% del voto más uno, o $40 \%$ si la diferencia con el segundo candidato es de al menos 10 puntos. Estos datos también reflejan un creciente nivel de aprobación a la gestión de Morales, que de acuerdo con diversas encuestas subió del $50 \%$ en enero a alrededor del $60 \%$ en diciembre, una mejora sustantiva respecto de un bajo nivel de aprobación del 38\% en enero del 2012.

Finalmente, fue también interesante observar en el 2013 la creación del Partido de los Trabajadores (PT) por la COB. Siguiendo el modelo brasilero de Lula da Silva, el PT boliviano tiene la intención de convertirse en el brazo político de la que todavía es la asociación gremial más importante de Bolivia. Sin embargo, el reciente acercamiento entre el gobierno y la cúpula de la $\mathrm{COB}$ ha puesto a la sombra a este partido por el momento.

\section{Corrupción y retardación de justicia}

La oscura sombra de la corrupción y los serios problemas de la justicia permanecieron en el 2013. Un caso simbólico fue la fuga de Jacob Ostreicher en diciembre. Ostreicher fue arrestado el 2011 por presuntas ganancias ilícitas. Su caso, no obstante, se convirtió en el hilo conector de una extendida red de corrupción que llegaba hasta altos niveles del ejecutivo, particularmente en los Ministerios de Gobernación y de la Presidencia. Luego de estar recluido durante 18 meses en la cárcel de Palmasola, y sin vistas de avanzar en el proceso en su contra, Ostreicher pasó a arresto domiciliario el 12 de diciembre. Al día siguiente, en un operativo coordinado por la organización internacional judía Aleph, Ostreicher aprovechó la poca vigilancia y fugó a su país de origen, los Estados Unidos, vía ingreso clandestino por Perú. Las labores de los actores y activistas Sean Penn (quien incluso se reunió con el presidente Morales en La Paz) y Mark Wahlberg en su favor fueron significativas y añadieron al interés de los medios internacionales. En respuesta, el gobierno boliviano lo declaró prófugo de la justicia y este proceso continúa en los tribunales bolivianos y sin vistas a ser resuelto.

Otro caso que también permanece irresuelto es el del denominado caso Terrorismo, con un juicio pendiente con más de 30 imputados. Este caso data de abril de 2009, cuando

5 Encuesta realizada por la empresa Tal Cual Comunicación Estratégica en todo el país, N= 2.250, realizada entre junio y julio del 2013, con un margen de error de 2,04\%. Otras encuestas muestran datos similares. 
en un operativo en Santa Cruz cayó abatido Eduardo Rózsa, acusado de ser el líder de un grupo irregular. Varios líderes cruceños fueron vinculados al caso y huyeron fuera del país, entre ellos el empresario Branco Marinkovic. Asimismo, el fiscal asignado al caso, Marcelo Soza, huyó a Brasil y solicitó asilo político denunciando que hubo excesos en el proceso y que se compró testigos en la investigación que lideró.

\section{Coyuntura social}

\section{Despenalización internacional de la hoja de coca}

El tema de la despenalización e industrialización de la hoja de coca tuvo una presencia permanente en la agenda política boliviana en el 2013. El año comenzó con el anuncio del Secretario General de la ONU, Ban Ki-moon, el 11 de enero, de aceptar el pedido boliviano de despenalizar el masticado de coca (conocido como acullico), penalizado por le Convención de Viena de 1961, a pesar de la objeción de 15 países (entre ellos Estados Unidos, Francia, Alemania, Rusia y México) de los 183 que se adscriben a este documento (al menos un tercio era necesario para lograr el veto). Este resultado es una victoria diplomática para Morales y refleja un gran esfuerzo durante el 2012 de despenalizar a la hoja de coca, lo que permitió a Bolivia retornar a las normas de la Convención.

A nivel doméstico, el gobierno mantuvo las mismas políticas para el control de la producción de coca, combinando mecanismos de control social, esto es el derecho de cada productor de coca de cultivar una parcela de coca (un "cato" o 0,16 hectáreas), combinadas con erradicación forzada en zonas no tradicionales. ${ }^{6}$ En su informe de cierre de gestión, la Fuerza de Tarea Conjunta (FTC) anunció la erradicación de 11.404 hectáreas de cultivos ilegales de coca, una cifra récord en el país. Si bien la producción de hoja de coca parece permanecer estable, hay varios indicios de que el procesamiento y el transporte de drogas por este territorio sigue en aumento, y que se relaciona al aumento de actividades criminales en Bolivia. En este tema, también llama la atención la expansión de otros cultivos, como la marihuana. Según el informe de la Fuerza Especial de Lucha Contra el Narcotráfico (FELCN), el decomiso de drogas en el país bajó en 42\% en 2013. Mientras que en el 2012 se confiscaron 36,3 mil toneladas de pasta base y clorhidrato de cocaína, en el 2013 esta cifra alcanzó las 20,9 mil toneladas. Si bien es posible que esta cifra refleje una caída en la producción, también es probable que la producción de drogas se esté diversificando en otras áreas, como ser la producción de marihuana, de la que se incautaron 76,5 mil toneladas en el 2013. La labor de la FELCN también incluyó la destrucción de alrededor de 5.500 fábricas clandestinas, 62 laboratorios de cristalización y 48 laboratorios de procesamiento de precursores químicos. El informe también citó que fueron incautados inmuebles y vehículos por un valor aproximado de US\$ 37 millones (7 avionetas, 796 vehículos y 95 inmuebles) (La Razón, 2013c). Si bien 
estos datos son mucho menores que en otros países, dan cuenta de que la industria de la droga sigue activa en este país.

Un elemento interesante en estos esfuerzos fue la presentación del "Estudio Integral de la Hoja de Coca" a mediados de noviembre. Esta investigación permite observar, de manera objetiva, el uso de la hoja de coca en Bolivia y ayudarán en el diseño de políticas públicas, por ejemplo para estimar la superficie de cultivos de coca que permitirían satisfacer la demanda legal en el país (la actual cifra es de 12.000 hectáreas fijada por la Ley 1.008 de 1988). Otro dato interesante de acuerdo con este estudio es que tres de cada diez habitantes adultos en Bolivia son consumidores habituales de la hoja de coca, un incremento del $15 \%$ respecto del 2006 . Este nivel de consumo tradicional justificaría el uso de al menos 14,7 mil hectáreas para una producción estimada de 20,7 mil toneladas de hoja de coca (DIGCOIN, 2013). La mayor parte del consumo se utiliza para el masticado $(37 \%)$ y para usos medicinales $(32 \%)$, con una menor proporción para ceremonias tradicionales. El estudio también muestra un claro sesgo de género, ya que la mayor parte de los consumidores (78\%) son hombres, y el consumo es mayoritariamente urbano $(67 \%)$ y distribuido por todo el país; contrario a la vieja percepción de que el uso de la hoja de coca era un fenómeno mayoritariamente rural-andino.

\section{Masacre en la cárcel de Palmasola}

Uno de los eventos más significativos del 2013, que también puso en evidencia la deficiente administración de justicia (que se estima que afecta al 80\% de los casos) y las precarias condiciones carcelarias, fue la masacre de reos en la cárcel de Palmasola en Santa Cruz. Esta prisión de baja y alta seguridad, diseñada para albergar algo menos de 2 mil reos y con una actual población carcelaria de 5.200 reos, fue el escenario de un violento episodio nunca antes visto en Bolivia. El 23 de agosto prisioneros de un bloque de celdas en la sección de alta seguridad que alberga alrededor de 500 reos (Chonchocorito) atacó a una banda rival en otro bloque (El Deber, 2013). Si bien episodios de violencia son comunes en cárceles con elevadas condiciones de hacinamiento, lo inusitado de este evento fue no solo el elevado nivel de violencia con el cual se desataron los hechos, sino también las carencias de la policía para prevenir esta situación. El ataque incluyó el uso de garrafas de gas que fueron utilizadas como bombas explosivas y lanzallamas, además del uso de armas de fuego, machetes y otros artefactos. El trágico saldo resultó en 35 personas muertas, incluyendo un niño de dieciocho meses que vivía con su padre en la prisión, además de al menos 37 otros heridos de gravedad. Parte de la pugna consistía en lograr el control interno de la prisión, que entre otros implica el recibir un "alquiler de vida" que pagan muchos internos a fin de tener un lugar en la prisión y preservar su integridad física. De acuerdo con fuentes internas, el monto varía según los ingresos estimados de cada reo, y oscila entre Bs. 200 (alrededor de US\$ 30) y Bs. 17.000 (US\$ 2.500) al mes. Luego de dos horas de violencia, la policía finalmente pudo controlar la situación con el uso de 700 efectivos. Este episodio ilustra una vez más, y de manera muy penosa, un anquilosado sistema de justicia y condiciones carcelarias infrahumanas, que todavía no tienen respuesta del Estado, a pesar de los numerosos esfuerzos de grupos promotores 
de los derechos humanos, como el Defensor del Pueblo, Amnistía Internacional y la propia Iglesia Católica.

\section{Procesos electorales}

\section{La oposición recobra espacio en el Beni}

El único proceso electoral significativo el 2013 fue la elección de gobernador en el departamento del Beni, la que sirvió en parte como un termómetro de las simpatías partidarias en el Oriente. La relación entre Morales y las elites políticas en este departamento han sido conflictivas desde el inicio de su gestión en el 2005, que en parte se explica por las sólidas raíces partidarias en ese departamento con partidos tradicionales como el Movimiento Nacionalista Revolucionario (MNR) y el ahora difunto Acción Democrática Nacionalista (ADN), así como de la simpatía con la agenda autonómica de los departamentos de la denominada "Media Luna". ${ }^{7}$ Parte de la conflictiva relación actual entre el ejecutivo y exautoridades departamentales se relacionaba con el denominado caso Chaparina del 2011. Este incidente se refiere a la violenta represión policial de alrededor de 1.500 manifestantes indígenas en la localidad de Chaparina en el Beni (de ahí el nombre) que participaban de la VIII marcha en defensa del TIPNIS protestando por la construcción de una carretera por su territorio. Este caso comprometió principalmente al ejecutivo, pero sirvió a las autoridades departamentales y al entonces gobernador del Beni Ernesto Suárez como plataforma para lanzar duras críticas contra el gobierno Suárez, que ya venía enfrentando un proceso formal del Estado en su contra por haber impulsado el referéndum de estatutos autonómicos departamentales en el 2008 y varios procesos relacionados con la malversación de fondos públicos, lo que incluyó una orden de arresto domiciliario a mediados del 2011, fue finalmente suspendido en diciembre de ese año de su cargo de gobernador. En diversas declaraciones Suárez lanzó duras acusaciones contra Morales y el MAS sobre las intenciones de derrocar a los gobernadores de oposición de la Media Luna. ${ }^{8}$ Siguiendo la normativa para las gobernaciones, y en una sorpresiva alianza, la Asamblea Legislativa del Beni posesionó al abogado del MNR Haysen Ribera, lo que fue posible gracias al apoyo del MAS.

La elección del 20 de enero por gobernador del Beni, por lo tanto, fue altamente significativa, ya que por un lado permitió que la legitimidad democrática finalmente retorne a las autoridades departamentales, pero por el otro demostró que los conflictos y la pugna política de vieja data siguen sin resolverse. En términos del proceso, la carrera electoral mostró dos candidatos fuertes. La ex-Miss Bolivia Jessica Jordán (que llevaba varios años militando en el MAS y que también fue candidata por este partido

7 Que además incluye los departamentos de Santa Cruz, Pando y Tarija y reciben su nombre por su forma geográfica combinada.

8 La relación entre Morales y el MAS con las gobernaciones de los departamentos de Pando, Tarija y Santa Cruz también fueron altamente conflictivas. Entre otros destacan el exilio voluntario del exgobernador de Tarija Mario Cossío al Paraguay, el proceso contra el exgobernador de Pando Leopoldo Fernández y los diversos procesos pendientes contra el gobernador de Santa Cruz Rubén Costas (ver Mendoza-Botelho, 2013, entre otros). 
en el 2010) con el apoyo directo de Morales, y Carmelo Lens en la oposición. El segundo representando a la asociación ciudadana Primero el Beni que aglutina a la oposición en ese departamento. Lens se impuso con 52,27\% de los votos contra $44,35 \%$ de Jordán (el resto dividido en otras dos fuerzas menores). Independiente de los elementos personales de cada candidato, esta elección fue una prueba importante con miras a las elecciones del 2014. Para el MAS sirvió como un termómetro para medir sus simpatías más allá de sus zonas tradicionales de influencia. Pero estos resultados fueron posiblemente más significativos para la oposición, no solamente por el hecho de recuperar una gobernación, sino por el hecho de que demostró las mejores chances de una oposición unida frente a un todavía popular MAS.

Un evento adicional que ilustra esta difícil relación en el Beni fue la salida al Brasil del senador de oposición Roger Pinto, quien permanecía con asilo político en la embajada de este país desde mayo del 2012. La solicitud de Pinto respondía a una serie de procesos de corrupción en su contra, a los que él consideraba parte de una persecución política a opositores clave. Por otro lado, el gobierno boliviano aseguraba que Pinto era responsable de actos de corrupción, incluyendo un fallo en su contra. Este evento generó malestar en lo que hasta el momento fue una fructífera relación entre Bolivia y Brasil. Parte del roce diplomático se relacionó a la inusual salida de Pinto del país, ya que el Estado le negó el apropiado salvoconducto, y quien con apoyo de miembros de a embajada brasilera (en un vehículo oficial) cruzó territorio boliviano y entró en Brasil en agosto del 2013. El gobierno boliviano manifestó su malestar por varios canales diplomáticos, pero esto no afectó la decisión de Brasil de aceptar a Pinto como asilado político. De acuerdo con el The New York Times (2014), este evento tuvo serias implicaciones internas en Brasil y culminó con el reemplazo del Ministro de Relaciones Exteriores por su presidenta Dilma Rousseff al día siguiente del ingreso de Pinto, posiblemente como medida para disminuir tensiones entre La Paz y Brasilia.

\section{Poder ejecutivo}

A diferencia de las gestiones anteriores, el 2013 comenzó con la decisión del presidente Morales de ratificar a todo su gabinete (ver Tabla 1). Esta decisión no dejó de ser cuestionada tanto por la oposición como por voces críticas dentro del MAS, en parte como secuelas del mencionado caso Ostreicher. Varios sectores de oposición y también del MAS pidieron la renuncia de algunos ministros como Romero en la cartera de gobierno, Suxo en la de Transparencia y Quintana en la Presidencia. Sin embargo, la decisión del Presidente fue firme y sustentada en los elevados niveles de ejecución presupuestaria de cada cartera y en una conformidad del balance técnico-político dentro del mismo. Sin embargo, considerando al 2013 como un año preelectoral, es posible que esta decisión refleje la necesidad del Presidente y Vicepresidente de estar rodeados de funcionarios no solo eficientes, sino también de comprobada lealtad. Asimismo, el no cambiar a ningún funcionario de alto rango fue una clara señal de que los sonados casos de corrupción del 2013 no habían penetrado a las altas cúpulas del MAS. 
Tabla 1. Gabinete ministerial 2013

Ministerio de Autonomía

Ministerio de Comunicación

Ministerio de Cultura

Ministerio de Defensa Nacional

Ministerio de Desarrollo Productivo y Economía Plural

Ministerio de Desarrollo Rural y Tierras

Ministerio de Economía y Finanzas Públicas

Ministerio de Educación

Ministerio de Gobierno

Ministerio de Hidrocarburos y Energía

Ministerio de Justicia

Ministerio de la Presidencia

Ministerio de Medio Ambiente y Agua

Ministerio de Minería y Metalurgia

Ministerio de Obras Públicas, Servicios y Vivienda

Ministerio de Planificación del Desarrollo

Ministerio de Relaciones Exteriores y Culto

Ministerio de Salud y Deportes

Ministerio de Trabajo, Empleo y Previsión Social

Ministerio de Transparencia Institucional y Lucha Contra

la Corrupción
Claudia Peña Claros (1970)

Amanda Dávila Torrez

Pablo Groux (1968)

Rubén Saavedra (1960)

Ana Teresa Morales Olivera

Nemesia Achacollo (1967)

Luis Alberto Arce Catacora (1963)

Roberto Aguilar Gómez (1958)

Carlos Romero Ballivián (1966)

Juan José Sosa (1963)

Cecilia Ayllón Quinteros (1959)

Juan Ramón Quintana (1959)

José Antonio Zamora

Mario Virreira Iporre (1949)

Arturo Vladimir Sánchez Escobar

Viviana Caro

David Choquehuanca (1961)

Juan Carlos Calvimonte (1966)

Daniel Santalla Torres (1948)

Nardy Suxo (1961)

Fuente: Elaboración propia basada en varias fuentes informativas. Para algunos datos biográficos ver Mendoza-Botelho (2013).

\section{Poder legislativo}

La Asamblea Legislativa Plurinacional aprobó 131 leyes de distinta significación en el 2013 (La Razón, 2013f). Igual que en la anterior gestión, la dispersión de los partidos de oposición dentro de la Asamblea, el Plan Progreso Bolivia-Convergencia Nacional (PPB-CN), Unidad Nacional por el Consenso (UN-PC) y Alianza Social (AS) les impidió hacer frente a una agenda dominada por el MAS. Entre la legislación aprobada se encuentran 29 leyes relacionadas al encuentro plurinacional del 2012 denominado "Para profundizar el Cambio", que refleja la estrategia de desarrollo del MAS con énfasis en reformas económicas y de infraestructura. Del total de leyes destacan la Ley General del Turismo, la Ley de Servicios Financieros, la Ley del Sistema Nacional de Seguridad Ciudadana y Ley contra el avasallamiento de tierras.

Posiblemente la norma más conflictiva fue la Ley de Aplicación Normativa (Ley $\mathrm{N}^{\circ} 381$, 21 de mayo de 2013), que viabilizó la reelección de Evo Morales y Álvaro García Linera 
luego del fallo emitido por el Tribunal Constitucional Plurinacional. La nueva Constitución boliviana permite la reelección del Presidente solo por un período consecutivo. Técnicamente, Morales ha completado dos períodos consecutivos en la presidencia. El argumento del MAS, no obstante, fue de que la primera gestión de Morales se dio durante la antigua constitución (que no permitía la reelección inmediata y limitaba el mandato del Presidente a dos períodos como máximo) y por lo tanto no sujeta al cambio constitucional del 2009. Este fue un golpe duro, pero esperado, para la oposición, cuyos argumentos legales no fueron suficientes y que además afectaba un acuerdo explícito logrado en el 2008 en el que Morales aceptaba ser reelegido solo por un período adicional (acuerdo que ayudó a romper un empantanamiento en la Asamblea Constituyente). Las fuerzas de oposición clasificaron a este fallo como una manipulación directa del nuevo sistema constitucional y de sus instituciones por parte del MAS.

\section{Agenda internacional}

Bolivia tuvo una agitada agenda internacional en el 2013, donde destacaron el liderazgo de Bolivia en el G77 + China, además de la demanda en la Haya contra Chile por el tema del mar. En términos de alianzas, el lanzamiento del primer satélite boliviano, el Tùpac Katari (TKSAT-1), refuerza una fructífera colaboración con China. Asimismo, el fallecimiento del presidente Hugo Chávez de Venezuela en el 2013, posiblemente el aliado internacional de mayor peso de Morales, causó impacto en cuanto al futuro de las alianzas regionales.

\section{El avión presidencial}

Un evento de alta significancia, y que puso a Bolivia en los titulares de la prensa internacional, fue el aterrizaje forzado del avión presidencial en Viena el 2 de julio durante su ruta de regreso luego de la participación de Morales en Moscú en un Foro de países exportadores de gas. El incidente comenzó con la negativa de Portugal de permitirle aterrizar en su territorio para recargar combustible, seguido por la negativa de Francia de darle acceso a su espacio aéreo, igual que Italia, lo que obligó al avión a realizar un aterrizaje forzoso en Austria. El principal motivo era la sospecha de que Edward Snowden, prófugo de la justicia norteamericana por alegaciones de espionaje y temporalmente asilado en Rusia se encontrase en el avión. Tras varias horas de negociaciones, que incluyeron la visita del Presidente de Austria, Heinz Fisher, finalmente Francia, España e Italia autorizaron el uso de su espacio aéreo.

La reacción en Bolivia fue inmediata. El vicepresidente Álvaro García Linera fue enfático en sus declaraciones, indicando que Morales estaba "secuestrado por el imperialismo", llamando a las clases sociales del mundo a pronunciarse sobre este atropello (La Razón, 2013b). Asimismo diversas protestas emergieron en La Paz frente a las embajadas de Francia y la Unión Europea. Sin embargo, lo que dio a este episodio un elevado perfil internacional fue la solidaridad de diversos países latinoamericanos mediante sus 
líderes por medio de la Unión de Naciones Suramericanas (Unasur). A pedido del Presidente de Ecuador, Unasur convocó a una reunión de emergencia en la ciudad de Cochabamba, donde se emitió un declaración que entre otros exigía una disculpa formal de los países europeos involucrados. Esta cumbre contó con la participación de los presidentes de Argentina, Cristina Fernández; de Venezuela, Nicolás Maduro; de Ecuador, Rafael Correa; de Uruguay, José Mujica; y de Surinam, Desi Bouterse, además de altos funcionarios de Brasil y los embajadores de Chile, Perú y Colombia. En términos de relaciones internacionales es claro que estos países europeos cedieron a las presiones de los Estados Unidos, y en violación de la Convención de Viena de 1961 que garantiza el libre tránsito de mandatarios de Estado. No es que este tipo de acciones no hayan sucedido en el pasado, pero el elemento problemático es que fue un ejercicio concertado entre varios países, lo que puso en evidencia el tema de soberanía. Otro elemento importante es que Unasur demostró ser un canal expedito para la movilización regional, y posiblemente mucho más efectivo que la lenta reacción de la Organización de los Estados Americanos (OEA) que finalmente emitió una declaración solicitando explicaciones varios días más tarde (el 9 de julio), a pesar de las primeras acciones de su Secretario General Miguel Insulza. Eventualmente Francia emitió una disculpa alegando que fue una confusión de evidencia más que una acción política, excusa similar utilizada por España. Entretanto, Italia negó ninguna participación y Portugal mantuvo su postura en cuanto a problemas técnicos que impidieron el aterrizaje del avión presidencial en su territorio. Finalmente, este episodio también añade al calor preelectoral, ya que generó nuevamente un sentimiento nacionalista y de solidaridad con Morales, plenamente justificada, ante este atropello a normas internacionales, lo que ayuda al discurso antiimperialista del MAS en sus objetivos electorales con miras al 2014.

\section{Liderazgo internacional boliviano en el G77 + China}

Si bien el incidente del avión presidencial puso a Bolivia en los titulares internacionales por malos motivos el anuncio de que Bolivia liderará el G77 + China el próximo año, que incluye organizar la cumbre de celebración de los 50 años de esta organización, mostró los esfuerzos de Bolivia de insertarse de manera estratégica en la agenda internacional. El 7 de noviembre la postulación de Bolivia a liderar el G77 en la Organización de las Naciones Unidas (ONU), respaldada por los países miembros de la Unión Sudamericana de Naciones (UNASUR), la Comunidad de Estados Latinoamericanos y del Caribe (CELAC) y la Alternativa Bolivariana para los Pueblos de Nuestra América (ALBA), fue aceptada por unanimidad por los miembros de este grupo. Una parte del éxito se debió a la labor del embajador boliviano ante la ONU Sacha Llorenti (y exmiembro del gabinete de Morales). Creado en 1964, el G77 aglutina a la mayoría de países de América Latina, África y del Sur de Asia como una alternativa a los dominantes países del norte, con alrededor de dos tercios de los miembros de la ONU y representando al 60\% de la población mundial. La reciente asociación de China en el 2012, luego de la Conferencia Rio+20, dio una nueva perspectiva a esta organización. 
Este prestigio, sin embargo, será oneroso para Bolivia. El gobierno boliviano ha aprobado un presupuesto inicial de US $\$ 21,2$ millones a ser destinados a las obras en preparación de la cumbre que tendrá lugar a mediados de junio del 2014 en la ciudad de Santa Cruz. Adicionalmente, el gobierno también ha destinado US\$ 1 millón para la oficina que coordinará el evento desde Nueva York. Este acontecimiento también requiere la movilización de las autoridades departamentales de Santa Cruz, incluyendo al gobernador Rubén Costas y al colorido alcalde de la ciudad de Santa Cruz, Percy Fernández, ambos duros críticos de la gestión de Morales. El G77 llegará a Santa Cruz con una cargada agenda de temas de discusión global y se espera que al menos 133 países participen de manera oficial de esta cumbre. Entre otros se discutirán temas relacionados al medio ambiente, comercio, estrategias de reducción de pobreza, seguridad e integración SurSur. Esta reunión es quizás el evento internacional de mayor envergadura que se haya realizado en Bolivia. Estratégicamente, este evento también desviará muchas de las energías políticas de las autoridades departamentales en el 2014.

\section{Demanda en La Haya}

La aspiración boliviana a una salida soberana al océano Pacífico luego de la pérdida territorial con Chile fue otro tema prioritario en el 2013. Los esfuerzos diplomáticos tomaron un nuevo rumbo con la aceptación de la demanda boliviana por la Corte Internacional de Justicia (CIJ) de La Haya el 24 de abril. Desde la perspectiva boliviana, este es un paso significativo en el tema marítimo, aunque no necesariamente es la misma para Chile, ni tampoco para el Perú, que sigue de cerca este proceso ya que cualquier resolución afectará también sus intereses, además de los efectos sobre el proceso pendiente que también tienen ambos países delimitando sus fronteras marítimas. Un elemento político importante es que Morales convocó la ayuda de varias figuras políticas, incluyendo todos los expresidentes y excancilleres. A principios de abril, Morales nombró al expresidente Eduardo Rodríguez Veltzé (en oficio 2005-2006) como Embajador Extraordinario con Representación Plenipotenciaria ante la CIJ, asignándole el liderazgo de esta difícil misión. Esta estrategia abierta da una dimensión distinta a la política exterior boliviana tradicionalmente sujeta a objetivos más inmediatistas. Asimismo, permite fijar un objetivo claro y con la esperanza de dar continuidad a un tema de alto interés nacional. Si bien este caso está siendo revisado en La Haya, el gobierno boliviano ha incorporado una cláusula reservándose el derecho de acudir a un tribunal de arbitraje si fuese el caso, a pesar de que Chile mostró poco interés en incluir este tema en conversaciones bilaterales.

\section{El Túpac Katari (TKSAT-1) en el espacio}

Sin duda alguna, uno de los eventos que marcó el 2013 en Bolivia fue el lanzamiento el 20 de diciembre del primer satélite de telecomunicaciones boliviano, el Túpac Katari 1 (TKSAT-1). La por demás excitante transmisión en vivo del lanzamiento desde la base de Xichang en China, mostró a un Evo Morales sonriente con una emoción no contenida que terminó en el aplauso de toda la comitiva, entre ellos el canciller Choquehuanca. Luego del despegue el Presidente dio su mensaje a la prensa expresando: “Emoción 
profunda. Nunca más estaremos incomunicados, como antes que estuvimos en la austeridad, en la oscuridad", para luego añadir: "El satélite Túpac Katari ya está en el cielo, es nuestra estrella que nos guiará" (La Razón, 2013e). Las imágenes del despegue fueron también memorables, con el logo "Gobierno Plurinacional de Bolivia" escrito en el costado del satélite bajo los nuevos símbolos patrios que combinan la tradicional bandera tricolor y la colorida bandera Whipala de unidad de los pueblos indígenas. El conteo regresivo al despegue en mandarín, contrastaba la narración de los reporteros en español, ilustrando lo que fue en el 2013 una fructífera relación entre Bolivia y China. El lanzamiento, por la empresa estatal de la República China Gran Muralla (nombre internacional Great Wall Industry Corporation), la misma que capacitó a más de un centenar de becarios bolivianos quienes se harán responsables de manejar el satélite, culmina la primera etapa de este proceso. El propósito de este satélite es doble, ya que por un lado espera reducir la dependencia tecnológica en el sector de telecomunicaciones con la transmisión de datos de internet, telefonía celular, televisión y promover la educación a distancia, y por el otro permitirá vender servicios satelitales a países vecinos y de esta manera ayudar a recuperar parte de los US\$ 302 millones que le costó al Estado boliviano, y financiados en buena parte por el Banco de Desarrollo de China. El efecto político también fue de gran impacto, y el Presidente ya anunció que esta fecha entrará en el calendario nacional como el "Día Espacial". Aunque hubieron algunas críticas de parte de la oposición por la magnitud del gasto, el sentimiento general fue de algarabía y de reconocimiento a los esfuerzos de Morales por haber promovido esta iniciativa. A fines de diciembre el satélite entró en su órbita definitiva y el manejo pasará a la recién creada Agencia Boliviana Espacial (ABE) durante el 2014.

\section{EVALUACIÓN GENERAL SOBRE EL FUNCIONAMIENTO Y CALIDAD DE LA DEMOCRACIA}

El 2013 presentó bastantes retos a la democracia en Bolivia, en un año preelectoral por demás intenso. El tema de corrupción fue uno de los constantes en la agenda política, donde destacaron varios de los casos pendientes que no encuentran respuesta en un sistema judicial anquilosado. Los procesos pendientes y los nuevos casos de corrupción, en un Estado en expansión no solo en el ámbito político sino también en el económico, son preocupantes en un país con una debilidad institucional crónica. Las falencias judiciales también fueron responsables de uno de los hechos luctuosos de mayor impacto en Bolivia en los últimos años, la masacre en la cárcel cruceña de Palmasola. Si bien los procesos electorales son fundamentales para la democracia, la salud y estabilidad de todo el sistema democrático resta en sus instituciones. No obstante, Bolivia sigue disfrutando un periodo de relativa estabilidad de carácter plenamente democrático. El éxito económico, del cual el Estado ha sabido aprovechar, está permitiendo mejoras sustantivas en las condiciones materiales de la ciudadanía, lo que en parte ha permitido disminuir algunas de las tensiones sociales, con preferencia aquellas ligadas a la redistribución de recursos, con los consecuentes efectos positivos sobre la democracia. Los efectos de la descentralización en Bolivia, que viene promoviéndose desde 1994, siguen siendo 
positivos en cuanto a permitir un desarrollo regional un poco más armónico, y a pesar de ciertos conflictos entre las autoridades nacionales y regionales, en parte debidos a una agenda autonómica que sigue pendiente.

En términos electorales, las cifras apuntan a una posible victoria de Evo Morales y del MAS-IPSP en el 2014, y que refleja un importante nivel de aprobación a su gestión. Por su parte, la oposición continúa dispersa y no ha logrado producir un discurso alternativo al actual modelo político y económico. Es más, la derecha política sigue sin articularse con la clase económica dominante que sigue creciendo en este país de disparidades. Pero la competencia está abierta y se esperan elecciones transparentes, en esta democracia que el 2013 estuvo al calor preelectoral.

Tabla 2. Hitos en la política de Bolivia durante el 2013

Enero 11 El Secretario General de la ONU acepta el pedido de Bolivia de despenalizar el masticado de hoja de coca (acullico).

Enero 20 El candidato de oposición Carmelo Lens es elegido como gobernador del Beni.

Abril 24 La Corte Internacional de Justicia en La Haya acepta la demanda de Bolivia de una salida soberana al mar contra Chile.

Mayo 1 El presidente Morales anuncia la expulsión de USAID, así como medidas económicas y de reformas al sistema de pensiones.

Paro de la COB.

Mayo 13 Se aprueba la Ley de Aplicación Normativa (Ley $N^{\circ}$ 381), que viabiliza la posible reelección de Evo Morales y Álvaro García Linera para un tercer período.

Morales es obligado a aterrizar en Viena luego de la negativa de países europeos de

Julio 2 otorgarle libre tránsito ante la sospecha de que el espía prófugo Edward Snowden se encuentre abordo.

Agosto 23 El exsenador Roger Pinto con asilo político en la embajada del Brasil cruza la frontera al Brasil.

Violencia se apodera de la cárcel de Palmasola en Santa Cruz.

Octubre 3 Morales aprueba financiamiento oficial para una dividida CIDOB por Bs. 8,3 millones.

Noviembre 7

Bolivia es elegida por aclamación en la ONU para liderar la cumbre aniversario del G77 + China en el 2014.

Diciembre 13 Jacobo Ostreicher, detenido como parte de un sonado caso de corrupción, se fuga hacia los Estados Unidos.

Diciembre 20 Bolivia lanza al espacio su primer satélite de telecomunicaciones, el Túpac Katari (TKSAT-1).

Diciembre 23 El presidente Morales se reúne con dirigentes de la CIDOB y Conamaq afines al gobierno. 


\section{REFERENCIAS}

British Broadcast Corporation (BBC). 2013. "Paso a paso, qué sucedió con el avión de Evo Morales". Edición en línea del 3 de julio. Acceso el 19 de febrero 2004 en http://www.bbc.co.uk/mundo/ noticias/2013/07/130703_bolivia_evo_morales_vuelo_cronologia_nc.shtml.

Dirección General de la Hoja de Coca e Industrialización del Gobierno de Bolivia (DIGCOIN). 2013. Estudio Integral de la Hoja de Coca. Informe Oficial. La Paz, Bolivia.

El Deber. 2013. "Ya son 35 los fallecidos por el ataque en Palmasola". Edición del 30 de agosto.

La Razón. 2013a. "Descuentos a maestros por el paro ascienden a Bs 15 MM". Edición del 29 de mayo.

La Razón. 2013b. "Francia, Italia, España y Portugal le negaron tránsito aéreo a Evo". Edición del 3 de julio.

La Razón. 2013c. "El decomiso de cocaína en el país cae en $42 \%$ en un año". Edición del 17 de diciembre.

La Razón. 2013d. "La inversión en sector petrolero llegará a US\$ 3.029 MM en 2014". Edición del 23 de diciembre.

La Razón. 2013e. "El satélite Túpac Katari fue puesto en órbita en una jornada histórica". Edición del 21 de diciembre.

La Razón. 2013f. "La Asamblea inicia receso; aprobó 131 leyes este año". Edición del 23 de diciembre.

La Razón. 2013g. "Bolivia cierra el año con 6,5\% de crecimiento y 35\% de participación del Estado en la economía". Edición del 26 de diciembre.

Los Tiempos. 2013. "Evo Morales expulsa a USAID de Bolivia”. Edición del 1 de mayo.

Mendoza-Botelho, Martín. 2013. "Bolivia 2012: Entre buenas y malas noticias". Revista de Ciencia Política 33 (1): $35-54$.

Página Siete. 2013. "CIDOB dividida por el gobierno de Morales". Edición digital del 25 de septiembre. Disponible en http:/ /www.paginasiete.bo/nacional/2013/9/25/cidob-dividida-gobierno-morales-1311. html. Acceso en enero 14, 2014.

The New York Times. 2013. "Brazil: Dispute in Bolivia Spills Over". Edición digital del 23 de agosto. Disponible en: http:/ / www.nytimes.com/2013/08/27/world/americas/brazil-dispute-in-boliviaspills-over.html?_r=0. Acceso en febrero 2, 2014.

Martín Mendoza-Botelho es Profesor de Política Económica en Eastern Connecticut State University en los EE.UU. y se especializa en temas de fortalecimiento institucional y desarrollo social, político y económico en países en desarrollo. También ha trabajado en temas de desarrollo y política internacional en varias organizaciones multilaterales, incluyendo la Organización de los Estados Americanos (OEA), la Comisión Económica para América Latina y el Caribe de las Naciones Unidas (CEPAL) y el Fondo de Naciones Unidas para la Infancia (UNICEF) en su país de origen, Bolivia. Tiene un doctorado (Ph.D.) de la Universidad de Cambridge en Gran Bretaña; una Maestría (M.Phil.) de la Universidad de Glasgow y Licenciatura por la Universidad Católica Boliviana.

http://martinmendozabotelho.wordpress.com

mendozabotelhom@easternct.edu 
